\title{
Flavionavia, una civitas romana en territorio de los Astures Transmontanos
}

\author{
NARCISO SANTOS YANGUAS*
}

El poblamiento prerromano de la desembocadura del Nalón constituye

la base para la configuración de la civitas astur-romana de Flavionavia en territorio de los pésicos; su significado como centro de producción agropecuaria y distribución económica (incluido el oro de la cuenca del Narcea) explica su desarrollo histórico al estar rodeada de un conjunto de villae.
The pre-roman settlement on the estuary of Nalon river can be taken as the basis for the development of the astur-roman civitas of Flavionavia in "pesicos" territory; its importance as

an agricultural, cattle-breeding and economic distribution center (including

the gold extracted along the Narcea basin) explains its historical evolution, being as it was surronded by a number of villae.

El centro de población astur-romano de Flavionavia, a pesar de aparecer registrado en algunos documentos antiguos, literarios (Ptolomeo por ejemplo), y epigráficos (la inscripción de Los Cabos...), no muestra en su registro arqueológico una continuidad que permita concretar su ubicación, el tipo de habitat a que corresponde, su sentido político-administrativo y/o económico del lugar, su etapa de mayor florecimiento..., o, por último, abrir nuevos interrogantes sobre su significado histórico en la época astur-romana de la Asturias antigua, así como de su final

* Universidad de Oviedo. 
como centro político-administrativo y núcleo de articulación del territorio cercano ${ }^{1}$.

Con motivo de la presencia romana entre las poblaciones astures se produciria el paso de la organización de aldea a la de ciudad (civitas), que el Estado romano adaptó al territorio anexionado a las comunidades septentrionales hispanas en general y a las astures en particular ${ }^{2}$. Dicho proceso entrañaría transformaciones de orden interno, sobresaliendo:

- la ocupación permanente de un centro de habitat (con presencia de población abundante en el mismo);

- la concentración, en número suficientemente amplio, de la población en dicho asentamiento;

- una delimitación tanto del espacio habitado como del suelo controlado para su aprovechamiento;

- una organización más o menos compleja políticamente de acuerdo con las peculiaridades de cada comunidad; $y$

- la consolidación de una diferenciación en clases o grupos sociales, sistema desconocido por los indígenas del Norte de la Península ${ }^{3}$.

Ello tendría su expresión en cambios arquitectónicos y urbanísticos, visibles a un doble nivel:

- en el tipo de construcciones privadas (domésticas); y

- en el surgimiento de edificaciones públicas, vinculadas con las funciones políticas, económicas y/o religiosas de la comunidad.

La plasmación de ese proceso, implícito en la conformación de las civitates por el Estado romano, entrañaría la organización político-administrativa del territorio de las distintas poblaciones integradas en las estructuras romanas ${ }^{4}$. Los pésicos, población de los astures, organizarían una parte al menos de su territorio en torno a uno de estos centros de funcio-

Como en otros muchos casos la administración romana incluiria a las poblaciones astures. junto con sus unidades suprafamiliares y los recintos de habitat correspondientes, en el marco del modelo romano de ciudad-territorio, de forma que tales grupos grntilicios se integrarían en civitates.

N. Santos, Asturias hasta la época medieval, Madrid 1996. págs. 77 ss.

Este proceso adquiere rasgos comunes a todos los núcieos que en tiempos romanos se ven marcados por la nueva organización administrativo-territorial. Cf. C. GonzAle7 Roman, Roma y la urbanización de Occidente. Madrid 1997. pág. 7.

4 Se diferenciaban asi de las civitates pregrinas. es decir de las comunidades que seguian regidas por su propio derecho (por lo que se opondrian a las colonias y municipios). Cf. F. JACQUES, Les cités de l'Occident romain. París 1990, pág. 19. 
namiento político-administrativo, socio-económico e ideológico-religioso, la civitas Paesicorum ${ }^{5}$, cuyo emplazamiento no se identifica con Flavionavia, aunque dicho núcleo de población estuviera enmarcado igualmente en el suelo correspondiente a dicho colectivo astur.

Sin embargo, este tipo de organización administrativo-territorial, sería distinto al proceso de municipalización que los emperadores Flavios pondrían en marcha en todo el imperio, en especial en las provincias occidentales del mismo, desde los años correspondientes al último tercio del siglo 1. Las civitates del cuadrante nordoccidental hispano, surgidas desde los primeros años del siglo "l (o a lo sumo en las décadas finales de la centuria precedente), se identificarían con unidades político-administrativas similares a los municipios de la Meseta; ahora bien, a pesar de que ambos tipos de población se rigiesen por una normativa jurídica derivada de las mismas instituciones, la existencia de las civitates astur-romanas se basaria en un poblamiento disperso en diversos centros de carácter rural (organizados de acuerdo con un principio de jerarquización) y no en núcleos urbanos de nueva planta, salvo en el caso de algunos de origen indigena (en número reducido), que adquiririan el estatuto municipal en época romana ${ }^{6}$.

Así los antiguos grupos de población de los astures, al convertirse en civitates, dispondrian de una organización paralela a la de los municipios de otras poblaciones del entorno ibérico, aunque sus habitantes viviesen en los mismos enclaves de asentamiento, incluidos en una estructura urbana centralizada, lo que supondría un elemento discordante en el seno de dichas comunidades ${ }^{7}$.

Por descontado que no encontramos en Flavionavia uno de esos complejos urbanos típicos de la Antigüedad clásica sino un antiguo núcleo de población indígena al que los romanos convierten en centro neurálgico de una región con unas funciones específicas (administrativo-territoriales, económico-comerciales, viarias...) en relación con la población indígena que habitaba el entorno de la desembocadura del Nalón ${ }^{8}$.

Las nuevas funciones administrativas, militares y económicas incidirían en la transformación (gradual y con cierta lentitud) del habitat prerromano. A

A. Garcia LinaRes y N. SANios, uNueva lápida romana hallada en Arganza (Tineo-Asturias)", MHA 10 (1989) 151 SS.

Como, por ejemplo. Gigia (= Gijón romano) o la propia Flavionavia.

La nueva situación no entrañaba la desaparición de las antiguas tradiciones y estructuras prerromanas, que seguirian vigentes tanto en el plano social como en el familiar

Dado que la aportación étnica de población externa (de origen romano yio itálico) seria es. casamente significativa. 
continuación trataremos de concretar los diferentes momentos históricos por los que iria atravesando, a lo largo de su existencia, el mencionado centro urbano de Asturias, partiendo del origen de su primitivo emplazamiento y analizando su desarrollo histórico hasta el final del mundo antiguo.

La documentación antigua acerca de este núcleo astur-romano no es explícita; las deficiencias que nos ofrece (escasez en número, el hecho de ser incompletas en el tiempo, de una época avanzada de la historia romana...) se ven paliadas en parte por su representatividad: tanto de la alusión de Ptolomeo en sus Tablas geográfico-históricas ${ }^{9}$ como de la inscripción fragmentada (sin campo epigráfico) de Los Cabos, en la que se refleja al único togado de territorio asturiano hasta la fecha ${ }^{10}$, parece desprende que dicho núcleo de habitat adquiriría, ya en el siglo ॥, el status de municipio.

Los restos arqueológicos vinculados con dicho emplazamiento resultan dispares, aunque corresponden en gran medida a una fase avanzada del Alto Imperio y la época posterior; en torno a la cuenca del Nalón en su tramo final se detecta la presencia de asentamientos castreños y villas romanas, formando parte de un mismo contexto histórico en etapas cronológicas sucesivas. Del período castreño existen indicios de un recinto de habitat en un montículo ubicado por encima de la actual iglesia de San Juan en Santianes de Pravia, en la margen izquierda del río, con las características propias de un centro de habitat indígena anterior a los romanos (emplazamiento en mediana altitud, elementos defensivos, topografía de dominio sobre el suelo próximo...).

Sobresale igualmente la existencia de un centro similar en la margen derecha de dicha corriente fluvial, conocido como los palacios (castro) de Doña Palla, con restos de monedas y tégulas romanas ${ }^{11}$; asi la entrada de la ría del Nalón (más profunda en la Antigüedad que hoy) estaría defendida y controlada desde sus dos márgenes, que constituían además sus dos zonas de acceso.

Por ello, debido a las condiciones topográficas de la desembocadura del Nalón serán elementos conectados con este tipo de asentamiento los principales restos descubiertos en dicho entorno geográfico; destacan los de la villa romana de La Magdalena de la Llera en Santianes de Pravia, donde en el año 1955 salió a la luz un muro romano de pequeño aparejo

\subsection{5}

F. JORDA, "Una nueva estela romana en Asturias", BIDEA 35 (1958) 430 ss.

Para más detalles remitimos a M. MALlo, "Tesorillo de denarios de Doña Palla", Archivum 19 (1969) 93 ss 
recubierto con estuco rojo, así como un pavimento de opus signinum y varios fragmentos de tegulae con rebordes ${ }^{12}$,

De la misma manera, y ya en una fase más avanzada, se han descubierto, en lugares próximos al conjunto eclesial de Santianes, restos de cimientos y muros de edificaciones antiguas, así como fragmentos de cerámicas finas y de inscripciones sepulcrales, sin olvidar ciertos trozos de tégulas planas... ${ }^{13}$, que nos ponen en conexión con una continuidad de poblamiento en dicho territorio desde un período histórico muy antiguo ${ }^{14}$.

Uno de los problemas con que nos encontramos a la hora de llevar a cabo la reconstrucción de la historia de este centro urbano lo constituye su emplazamiento. Ptolomeo se refiere, en la segunda mitad del siglo 11, a la existencia entre los habitantes de la Asturias de su época de dos núcleos de población de cierta relevancia, el primero de los cuales, Flavionavia, se hallaría ubicado en el territorio de los pésicos (2.6.5), no volviendo a aparecer con posterioridad en las fuentes literarias, mientras que el segundo, Lucus Asturum, se registra en la diplomática medieval y en escritos posteriores con frecuencia ${ }^{15}$.

Puesto que sólo es mencionada por el geógrafo de Alejandría (y ya en la fase final del Alto Imperio), se ha relacionado a Flavionavia con el centro de población más representativo del grupo social de los pésicos (confundiéndolo a veces con la capital de dichas población), que sería utilizado como enclave de relaciones maritimas y comerciales (unos objetivos que no perdería en los siglos medievales y modernos). Nos encontramos, pues, ante el puerto de salida de la producción aurífera de una parte de los yacimientos mineros de la cuenca del Narcea, en especial si tenemos en cuenta que la ría del Nalón constituiría un punto de evacuación del oro y de otros productos agropecuarios de la región por medio de la escuadra romana del Cantábrico ${ }^{16}$.

Según los grados de latitud que la asigna Ptolomeo, distintos a los correspondientes a la desembocadura del Nalón de acuerdo con el autor

J.M. Gonzaltz, "Restos romanos de la Magdalena de la Llera (Santianes de Pravia)", BCPM Oviedo 1 (1957) 201-203.

" Ver, entre otros, A.J. DE BANCES y VALDES, "Noticias históricas del concejo de Pravia". BRAH 58 (1911) 262ss.

* Sobre el topónimo de dicho enclave y los problemas que conlleva remitimos, entre otros, a N. SANTOS, "La ciudad astur-romana de Flavionavia: un avance a su estudio", MHA 19 (1998).

"La importancia de este segundo núcleo de habitat de los astures transmontanos requiere un: análisis monográfico, dado que su significado se acrecentaria al convertirse en nudo de comunicaciones (el hallazgo en su solar de una inscripción dedicada a los Lares Viales asi lo confirma).

Sobre estas cuestiones cf. N.SANTOS, "La evacuación del oro de Asturias en dirección a Roma", /l Congreso Peninsular de Historia Antigua. Coimbra 1994, pp.917ss. 
griego (no ubica, sin embargo, ambos accidentes del terreno a una distancia grande entre sí), habría que situar a Flavionavia en las márgenes de esa corriente fluvial y siempre en los alrededores de Pravia ${ }^{17}$, no muy lejos del litoral y un poco hacia el interior ${ }^{13}$. El emplazamiento de este centro urbano de los astures en época romana ha suscitado opiniones divergentes, aunque todas coinciden en situarlo en las inmediaciones de la costa y en los aledaños de alguna corriente fluvial de cierta consideración. Así, desde hace siglos se viene proponiendo su localización en la capital del concejo de Navia, tras descomponer el topónimo ptolemaico en dos (Flavio y Navia), y tener presentes las características que nos ofrece la ría de la corriente fluvial homónima en la actualidad (los poblados castreños de Coaña y Armental en sus dos márgenes, que controlaban y flanqueaban la bocana de entrada y salida al mar; Coaña como centro de recepción de los productos auríferos obtenidos en las explotaciones mineras del distrito lbias-Narcea; la posibilidad de que en dicha ría recalase cada cierto tiempo la escuadra del Cantábrico; la presencia de murias y topónimos antiguos, algunos de ellos vinculados con asentamientos agropecuarios en los lugares más llanos del territorio; el trazado de la red viaria romana, próximo al litoral, cuya continuación se rastrea igualmente en tiempos visigodos y medievales) ${ }^{19}$.

Se inclinan por su localización en la capital del concejo de Valdés (Luarca), sin argumento alguno que aclare dicha elección, investigadores como el Padre Flórez (considera que es en dicho territorio donde debe ubicarse la península de los pésicos a la que se refieren los autores antiguos) ${ }^{20}$; por su parte Bosch Gimpera y Aguado Bleye ${ }^{21}$ ubican su emplazamiento en Pravia sin ningún detalle que añadir al respecto ${ }^{22}$.

La historiografía actual converge en situar este centro de población en las proximidades de Pravia, y más en concreto en Santianes de Pravia, no sólo por la documentación histórica (restos arqueológicos sobre todo) sino

En ningún caso en la actual capital del concejo.

18 Algunos autores, como Diego Santos, siguiendo las indicaciones de Jose MANufl GonzALEZ, creen que se trataría del hito final de la Vía de la Mesa, que, proveniente del territorio leonés. llegaria hasta la costa cantábrica.

19 Dicha hipótesis arranca de RIESCO, MADOZ y CEAN BEFMUDEZ, habiendo sido defendida después por Fernandez Guerra, A. Blazquez, Somoza, Sanchez Albornoz, lopez Cuevillas y SchulTEN (quien recoge, en parte al menos, la opinión de sus predecesores en su Geografia y etnografia antiguas de la Peninsula lbérica, Madrid 1959, págs. 107-108).

20 En España Sagrada 15, págs. 46-47.

21 Historia de España de R. Menéndez Pidal, Madrid 1935, 2, págs. 260 y 268.

${ }^{2 ?}$ Las distintas hipótesis se recogen en J. SANios, "Asturias en la organización político-administrativa romana de Hispania en época altoimperial», Historia general de Asturias, Gijón 1982 1, págs. 154-155 
también por su continuidad de poblamiento desde una época muy antigua, a pesar de que no se corresponderia con la capitalidad de los pésicos, como se ha pretendido en ocasiones de forma equivocada ${ }^{23}$.

Los restos materiales hallados en el territorio de esta aldea praviana o en sus inmediaciones (la villa romana de la Magdalena de la Llera ${ }^{24}$; la villa romana sobre la que se construye la iglesia dedicada a san Juan, sin duda aprovechando la existencia de una capilla o iglesia paleocristiana; los topónimos de raíz latina de la zona; los restos de construcciones antiguas, fragmentos de cerámica fina, tejas planas y barros toscos, cocidos y sin esmalte, hallados en el valle de Posada en Bances; sepulturas con restos humanos y fragmentos de inscripciones sepulcrales de tiempos romanos ${ }^{25}$; la estela del togado de Los Cabos...) denotan un proceso de romanización, incluido un aprovechamiento intensivo (agropecuario) de los recursos económicos de la zona en tiempos romanos, en especial durante el Bajo Imperio.

Por ello, a pesar de los problemas de la reconstrucción histórica del emplazamiento de Flavionavia, sobre todo en lo que se refiere a su desarrollo evolutivo en las primeras fases de su existencia, una cosa resulta evidente: el origen de su poblamiento no pudo arrancar de tiempos romanos. Al igual que sucederia con otros enclaves a los que la administración romana revestiría de un sentido nuevo tras introducirlos en el proceso de municipalización generalizado de todo el Imperio ${ }^{26}$, los momentos iniciales del habitat relacionado con el entorno de lo que acabaría siendo nuestro centro urbano corresponderian a tiempos prerromanos.

La ubicación de dicho núcleo de población, que se conecta con un recinto fortificado castreño, no se identifica exactamente con lo que sería después el emplazamiento astur-romano de Flavionavia, aunque resulta fácil suponer que los habitantes del mismo se desplazarian con posterioridad a dicho asentamiento (ya en época altoimperial romana) ${ }^{27}$ : por encima del lugar ocupado en la actualidad por la iglesia consagrada a san Juan en Santianes de Pravia existe un montículo que por los restos de

${ }_{23}$ Ver, por ejemplo, J.M. GonzAlez, "Flavionavia, antigua población de los pésicos", págs. 32 ss. Sobre este último aspecto volveremos más adelante.

24 J.G. GonGEs, Les villas hispanorromaines, París 1979, pág. 333.

Elementos descritos ya con cierta profusión por parte de F. de SElGAS. La primitiva basilica de Santianes de Pravia (Oviedo), Madrid 1902

2e Recordar el caso de Gigia = Gijón romano. Cf. N. SANTos, "Gigia, la ciudad romana de Gijón", MHA 17 (1996) 215 ss.

Como sucederia, por ejemplo, con los pobladores de la Campa Torres (antigua polis Noega) con respecto al asentamiento de Cimadevilla en Gijón (Gigla) con los habitantes del recinto castreño de Castiello con respecto a Lucus Asturum (Lugo de Llarera) entre otros. 
cerámica en superficie, la estructura de su emplazamiento, su localización y sus características se corresponde con un yacimiento anterromano ${ }^{28}$. Su topografía responde a objetivos de control territorial con respecto a la margen izquierda del rio Nalón; además de esas características propias de un asentamiento de mediana altitud, sobresalen sus elementos defensivos naturales y artificiales, lo que contribuiría a esa posición de dominio sobre el suelo cercano (las tareas de vigilancia se completarían con lo que sucedería en la margen derecha, donde se asentaba el recinto castreño de Doña Palla, que continuaría habitado en tiempos romanos, de acuerdo con lo que se deduce de la presencia de monedas muy antiguas ${ }^{29}$ ).

Al contrario de lo que sucedería con el poblado castreño de Santianes, este centro no sería abandonado en tiempos romanos como consecuencia de su traslado a un enclave de nueva creación, sino que perviviria durante mucho tiempo, llegando a reforzarase en sus estructuras defensivas ( $y$ tal vez en cuanto a su importancia demográfica) durante los siglos bajoimperiales y la época medieval como lugar de control (fortín o fortaleza) del territorio próximo a la desembocadura del Nalón ${ }^{30}$.

A medida que nos adentramos en el período imperial, y tras la fase de articulación administrativo-territorial del suelo anexionado tras las guerras astur-cántabras, los habitantes del emplazamiento castreño de Santianes (o una parte de los mismos) buscarian alojamiento en lugares más próximos a la vega del Nalón, donde los nuevos centros de aprovechamiento económico les ofrecerían mejores posibilidades de vida ${ }^{31}$, mientras que otro grupo de ellos se establecería con posterioridad en el emplazamiento correspondiente al centro urbano de Flavionavia ${ }^{32}$.

Por ello resulta fácil suponer que, como en el caso de la ciudad romana de Gigia, que ejercería desde el siglo I de nuestra era (y sobre todo en el transcurso de la centuria siguiente) una atracción enorme sobre los habitantes de Noega (asentamiento castreño de la Campa Torres), hasta el punto de que casi toda la población se desplazaría hasta dicho centro urbano, los in-

\footnotetext{
28. Hace algunos años labores practicadas en el mismo dejaron al descubierto restos de construcciones que se vinculaban con su sistema defensivo, asi como con sus edificaciones internas.

29 M. MALLo «Tesorillo de denarios de doña Palla», Archivum 19 (1969) 93 ss.

so La princesa Doña Palla, de quien recibe el nombre, llegaria desde la corte de León para gobernar dicho territorio.

31 Simultáneamente se daría paso a un marco de relaciones sociales distintas, que facilitarían el arraigo de la estructura social romana (aunque no con una correspondencia completa en sus ordines y grupos sociales).

32. Nos hallamos ante un proceso común a todas las regiones hispanas. Cf. J.M. ABASCAL y U. EsPINOSA, La ciudad hispano-romana. Privilegio y poder, Logroño 1989, págs. 71 ss.
} 
dígenas del recinto de Santianes dirigirían sus pasos hacia el nuevo centro de Flavionavia, surgido (al menos en parte) por la aportación de los pobladores de los enclaves cercanos ${ }^{33}$.

El proceso que se abre para dicho territorio tras su conquista por parte romana en las décadas finales del siglo I a.n.e. supondría un avance para la región a lo largo de las centurias del Alto Imperio como resultado de la explotación económica de la zona y de la conversión de la parte final de la cuenca fluvial del Nalón en vía de salida para dichos productos (no sólo agropecuarios sino también mineros, procedentes en este caso de los tajos correspondientes al valle del Narcea).

El momento de inflexión (alteraciones y cambios en el seno de las comunidades indígenas) vendría dado por la presencia romana en el cuadrante nordoccidental hispano y la conquista del mismo ${ }^{34}$; este hecho no supondría ni a corto ni a largo plazo un arrasamiento del poblamiento sino un control administrativo de la zona y una articulación del suelo con vistas a su aprovechamiento económico. Para lograr dichos objetivos se dispondria de grupos reducidos de militares, que integrarian pequeñas unidades de tropas emplazadas en los enclaves más estratégicos de la zona (en nuestro caso en un primer momento esta función la cumpliría el recinto castreño de Doña Palla) ${ }^{35}$.

Hasta la actualidad ningún indicio corrobora lo que supondrían estos primeros momentos de presencia romana en la región, algo que no debería extrañarnos puesto que en similar situación de oscuridad nos hallamos con respecto al resto del territorio habitado por los astures ${ }^{36}$. Durante los primeros cincuenta años de presencia efectiva (más de tipo administrativoterritorial que de otra forma) de los romanos en el Norte peninsular sus esfuerzos se centrarian en la implantación de los mecanismos y adelantos técnicos, tanto mineros como agropecuarios, destinados a introducir a los indígenas en los parámetros de la economía mediterránea de la época ${ }^{37}$.

\footnotetext{
33 Los pobladores de otros núcleos prerromanos. como el de Doña Palla en la margen derecha del Nalón, acudirian también a vivir a dicho centro urbano, que se fortalecería con la aportación de nuevos grupos humanos.

3. Las consecuencias de esta presencia militar se recogen, entre otros, en N. SANTOS, "La conquista romana del N.O. de la Peninsula lbérica". Latomus 41 (1982) 5ss

35 Objetivos similares cubriria el torreón detensivo de Coaña en la ría del Navia, que serviria de alojamiento a un pequeño grupo de soldados, asi como de receptáculo de los productos aurí feros obtenidos en la cuenca del Ibias-Navia (que ese mismo destacamento militar controlaria)

35 Quizás las excavaciones futuras saquen a la luz elementos clarificadores de esta cuestión, ya que la documentación escrita (literaria y/o epigráfica) permanece muda.

3: Simultáneamente las comunidades de los astures se irıan intruduciendo (y asimilando) en los parámetros propios de la organización político-administrativa y económico social romana.
} 
Esta etapa inmediata al final de las guerras pudo ser aprovechada por los romanos para llevar a cabo el reclutamiento de una parte de la población de los astures (los más jovenes) con vistas a su enrolamiento en las unidades de tropas auxiliares romanas ${ }^{38}$; la participación en el ejército pasó a ser un medio de promoción social en el marco de sus comunidades respectivas, ocasionando una falta de mano de obra en el aprovechamiento de los recursos económicos de la región, sobre todo porque, desde Augusto, la política romana se orientaba hacia el establecimiento de estas poblaciones en enclaves llanos con vistas a una mejor explotación de los recursos agropecuarios de su entorno ${ }^{39}$.

El suelo a explotar por los romanos en la desembocadura del Nalón ofrecía casi de forma exclusiva buenos recursos agropecuarios, como se observa tanto en la parte final de la cuenca del Narcea antes de su confluencia con el Nalón (vegas existentes antes y después de Cornellana en ambas márgenes, como por ejemplo Corias, Quinzanas...) o en el recorrido de este último hasta su entrada en el Cantábrico (vegas de Forcinas, Peñaullán, Bances, Santianes, Ranón, Los Cabos...).

No es de extrañar que la zona aportase ya desde el siglo I evidencias de la presencia de asentamientos de población y de aprovechamientos agropecuarios en el entorno territorial próximo a los ríos, como sucede por ejemplo, en el término de Santianes de Pravia, con la villa descubierta en el lugar conocido como La Magdalena de la Llera, yacimiento cuyas primeras noticias parecen remontar al año 1777, aun cuando hasta 1955 , con ocasión de la realización de una trinchera para la vía del ferrocarril, no aflorasen restos arqueológicos que relacionasen dicho enclave con un asentamiento astur-romano ${ }^{40}$.

En contraste con la intensificación de esta producción agrícola y ganadera no hay indicio alguno de aprovechamiento minero en la zona; no quiere decir que, de forma indirecta, la desembocadura del Nalón no se conectase al menos con la evacuación de una parte de los productos mineros obtenidos en la cuenca del Narcea, que encontrarian en la vía de comunicación paralela a la principal corriente fluvial de Asturias su salida al mar en tiempos romanos. Todo cuadra mejor si tenemos en cuenta que

38 Tras su adiestramiento en los campamentos legionarios de suelo hispano serían trasladados a las lineas fronterizas que era preciso defender frente a los pueblos exteriores (en especial el limes del Rhin y del Danubio). Cł. N. Santos, El ejército y la romanización de los astures, Oviedo 1981, págs. 123ss.

Floro 2.33.58-59

40 Sobre el contenido de dicho descubrimiento remitimos a J.M. GonZALEZ, "Restos romanos de la Magdalena de la Llera (Santianes de Pravia)", págs. 201ss. 
desde las décadas finales del siglo । la zona central asturiana adquiere un significado histórico especial como consecuencia de que el triángulo formado por los enclaves de Flavionavia, Lucus Asturum y Gigia controlarían gran parte de la producción económica, así como las principales rutas viarias ${ }^{4}$.

A este proceso de intensificación de la producción y de articulación del territorio, con el consiguiente aumento demográfico, contribuiría la labor de los emperadores Flavios en el cuadrante nordoccidental hispano, incluyendo su política de urbanización y municipalización ${ }^{42}$.

Aunque resulte extraño que hasta la fecha no se haya descubierto en dicho entorno territorial ningún documento epigráfico (no ya monumental u honorífico, pero al menos votivo o funerario), en las décadas finales de ese siglo I el enclave astur-romano de Flavionavia tomaría un auge especial, si es que dicho centro urbano no se configura entonces como núcleo administrativo de esta parte del territorio pésico.

Su importancia cada vez más descollante se relaciona con el hecho de que en torno a él y durante este periodo histórico (tal vez de forma más acusada desde las primeras décadas del siglo II) arraigaría un entramado de comunicaciones, que o bien enlazaba este enclave costero con las tierras del interior al haberse convertido en el hito terminal de la vía de La Mesa (que, desde el territorio leonés, desembocaba en el Cantábrico) o bien capitalizaba las actividades económicas que, próximas al litoral, utilizaban el trazado de Lucus Asturum a Lucus Augusti ${ }^{43}$. Esta vinculación con la red viaria romana más activa durante el Alto Imperio de toda Asturias haria que Flavionavia se viera inmersa en los circuitos económico-comerciales que harian evolucionar en su organización interna a los habitantes de dicho territorio.

Ahora bien, ¿qué estatuto jurídico alcanzó este centro astur-romano y en qué momento de su historia?. Se ha afirmado, tal vez un poco a la ligera, que a partir de la dinastía de los Flavios sería municipio, incardinando la adquisición de dicho status político en el hecho de que a su situación estratégica añadiría su contexto económico ${ }^{44}$.

\footnotetext{
Sin duda uno de los territorios de mayor relevancia de los astures.

Para más detalles ver G. FABRE, "Le tissu urbain dans le Nord-ouest de la Péninsule Ibérique", Latomus 29 (1970) 314 ss.

Cornellana (en la cuenca del Narcea) seria el punto de enlace. Cf. J.M. GonzAltL, «Man siones en el trayecto de la vía romana Lucus Asturum-Lucus Augusti., Archivum 6 (1956) 287ss

4a J. SAnTos, "Asturias en la organiazación político-administrativa romana de Hispania en época altoimperial', pág. 155
} 
¿Qué manifiesta la documentación escrita al respecto?. Si excluimos la referencia ptolemaica a dicho centro urbano pésico (en un momento avanzado del siglo $\|$ d.n.e.), el único testimonio que puede hacernos pensar que se convertiría en municipio lo constituye el monumento epigráfico de Los Cabos, en el que se representa a un togado romano (tal vez miembro de la oligarquía municipal de Flavionavia, en cuyo centro urbano desempeñaría alguna de las magistraturas municipales más significativas -el duumvirato o la edilidad-) ${ }^{45}$.

Dicha estela (¿funeraria?, ¿honorífica?, ¿o ambas cosas a un mismo tiempo?) se hallaba en su origen empotrada en una antigua capilla, como material constructivo reutilizado por su consistencia pétrea; con posterioridad (de ahí el estado de conservación fragmentado en que se encuentra) formaría parte de un saledizo de un edificio rural (horreo), sufriendo por ello un corte en su parte derecha.

El fragmento epigráfico ofrece dos elementos a analizar: la representación humana y el contenido escrito. La escultura figurada se corresponde con un mediorrelieve representando a un hombre togado y esta realizada de acuerdo con parámetros artísticos propios de un arte provincial (el de los indígenas astures en época romana). Toda una serie de características, como la anatomía apenas perceptible del personaje (sobre todo en lo referente a los rasgos fisiognómicos), la rigidez que desprende la figura, el tipo de modelado, los pliegues de la toga representados de forma convencional..., responden a la obra de un cantero con muy pocos recursos artísticos y expresivos; sin embargo, se logra encajar la disposición de la figura con la mano levantada en actitud pacífica, que rememora las representaciones de togados bajo hornacina tan típicos de la escultura (medios o bajorrelieves) romana, en las que los personajes recogen con la mano izquierda su toga mientras elevan la derecha como saludo ${ }^{46}$.

Por su parte el campo epigráfico ha desaparecido casi por completo al fracturarse la piedra, conservándose el nombre de un personaje (ARIO o VARIO SESTIO, en ningún caso VARIO F(ilio) SESTI como propuso en su día F.Jordá), cuya existencia, según el tipo de letra, puede hacerse remontar o a finales del siglo 10 a las primeras décadas de la centuria siguiente, pero no a la segunda mitad de esta última ${ }^{47}$.

45 Para más detalles ver F. JOROA, "Una nueva estela romana en Asturias", págs. 430ss.

45. Sobre esta clase de figuraciones remitimos, entre otros, a A.GARCIA Y BELLIDO, "Sobre un tipo de estela funeraria de togado bajo hornacina", AEA ns 115-116 (1967) 110ss. 161-162.

L. Fernandez Fuster, "Un nuevo núcleo artístico en el Norte de España», AEA 25 (1952) 
Las características del monumento, la representación del individuo figurado en la inscripción (el único togado de tiempos romanos conocido hasta la actualidad en Asturias), la ubicación originaria de dicha pieza ${ }^{48}$, su sentido político-administrativo, así como otros aspectos que la rodean nos permiten afirmar que este centro de poblamiento antiguo pudo haber adquirido el estatuto de municipio en los últimos años del siglo 10 en los inicios del siguiente.

Esto se produciría en conexión con esa serie de factores que, arrancando de tiempos de los Flavios, iban a contribuir al gran avance histórico del cuadrante nordoccidental hispano en su conjunto, y entre los que sobresalen la concesión del ius Latii por Vespasiano ${ }^{49}$, la división administrativa del territorio peninsular ibérico en conventus jurídicos, incluidos los del Noroeste ${ }^{50}$, la participación de indígenas de dicha zona en las unidades de tropas auxiliares del ejército romano ${ }^{51}$, la explotación intensiva de los recursos mineros de oro de los diferentes distritos de la región ${ }^{52}$, etc...

De acuerdo con las características y datación de las leyes municipales flavias de la Bética, en estado fragmentado ${ }^{53}$, a pesar de que nos permiten conocer unas tres cuartas partes de dicha legislatura municipal, podemos afirmar que, aunque Vespasiano concediera el derecho latino a toda Hispania en el año 73-74, un gran número de estos centros urbanos no se organizarian al modo romano hasta Domiciano ${ }^{54}$, e incluso más tarde.

¿Por qué razón el primer autor antiguo que presenta una panorámica sobre el proceso de municipalización-urbanización de la Península por Roma, Plinio el Viejo ${ }^{55}$, no documenta la existencia de Flavionavia como centro ur-

48 Que sin duda sería dislocada de su emplazamiento para ser desplazada (ya en época miedieval) donde pudiera servir de elemento constructivo; por ello resulta lógico pensar que su ubicación primigenia se relacionaria con el asentamiento de Flavionavia, centro politico-administrativo y económico de toda la zona durante la Antigüedad (romana y visigoda).

44. R. WIEGELS, "Das Datum der Verleihung des ius Latii and die Hispanier. Zur Personal- und Municipalpolitik in den ersten Regierungsjahren Vespasians". Hermes 106 (1978) 196ss.

50 L. SANCHO ROCHER, "LOS conventus iuridici en la Hispania romana", Caesaraugusta nS 45-46 (1978) 171ss. Cf. N. SANTOS, "Los conventus juridicos del Noroeste peninsular", BIDEA n" 115 (1985) 599ss.

5. Ver, entre otros, N. SANTOS, El ejército romano y la romanización de los astures, Oviedo 1981, y Galicia y el ejército romano, Oviedo 1988.

$5 \%$ A. MONTENEGRO, "Problemas y nuevas perspectivas en el estudio de la Hispania c'e Vespasiano", HAnt 5 (1975) 7ss.

s3 Sobre todo las de Salpensa y Malaca, así como, más recientemente, la de $1 \mathrm{rni}$. Ct. J. GonZALEL. "The lex Imitana: a New Copy of the Flavian Municipal Law". JAS 76 (1986) 147ss.

54 F. JACQUES, Les cités de l'Occident romain pág. 13.

5: B. Galsterer-Krol L, "Zu den spanischen Städtelisten des Plinius", AEA 48 (1975) 120ss Para más detalles H. GALSTERER, Untersuchungen zum römischen Städtewesen auf der iberischen halbinsel, Berlin 1971. 
bano?. Porque cuando el naturalista escribió su obra (comedios del siglo । d.n.e.), dicho emplazamiento no había logrado suficiente entidad como núcleo de población, centro territorial, demográfico y/o político-administrativo de la región que poco después se articularía y organizaría en torno a él.

Pero, además de que estarían próximos los ecos de los últimos levantamientos de los astures contra el poder romano, no se habían adaptado todavía los mecanismos técnicos de la minería vinculados al aprovechamiento de los recursos auríferos del Suroccidente asturiano, lo que se iba a convertir, con el paso de los años, en el motor principal del surgimiento de centros de población entre los astures transmontanos ${ }^{56}$.

Como consecuencia de la aplicación a algunos de los núcleos de habitat del Norte peninsular de la lex Flavia municipalis, aunque sus primeros pasos en la historia remontarían a las décadas anteriores, adquiriria en un plazo no corto (tampoco necesariamente en tiempos de Vespasiano) las caracteristicas inherentes a un municipio, bien en época flavia, bien durante el reinado de alguno de los dos primeros emperadores de la centuria siguiente) ${ }^{57}$. En ese momento hemos de situar su florecimiento, en el que tendría mucho que ver la puesta en explotación de los yacimientos mineros del Occidente de los astures y la evacuación de los productos económicos de dicha zona.

Una cuestión diferente se plantea, en conexión con estas funciones de articulación, ordenación y aprovechamiento del territorio próximo a su emplazamiento (funciones de tipo administrativo-territorial), con respecto a la situación estrictamente política de dicho centro. Algunos investigadores de nuestros días se refieren a ella como antigua población de los pésicos ${ }^{58}$, mientras que otros llegan a considerarla como capital o centro político-administrativo de dicho pueblo.

La segunda opción no parece la adecuada, puesto que el descubrimiento de una inscripción en Arganza (concejo de Tineo), en que se documenta la presencia de la $c$ (ivitas) $P$ (aesicorum) ${ }^{59}$, excluye la identificación

56 No parece descabellado pensar que nuestro núcleo de población remontaria en su origen (y/o importancia) a las décadas finales del siglo I, a pesar de que hasta la centuria siguiente no adquiera el culmen de su importancia como centro supervisor de la evacuación, a través de la desembocadura del Nalón, de los productos auriferos obtenidos en las cuencas del Narcea y Pigüeña, así como de algunos de sus más importantes afluentes.

57 Aunque su toponimia parece vincular a dicho enclave con la dinastia de los Flavios, tal vez la adquisición del estatuto municipal tendría lugar unas décadas después.

58 J.M. GonzÁlEZ, "Flavionavia, antigua población de los pésicos", págs. 32ss.

59 Para más detalles ver A. GARCIA LINARES y N. SANTOS, "Nueva lápida romana hallada en Arganza (Tineo-Asturias)", MHA 10 (1989) 151ss. 
de Flavionavia con el centro de habitat que serviría de capitalidad al grupo de población de los pésicos. El lugar en que se halló dicha pieza, a pesar de su dislocación del emplazamiento originario (marco geográfico de los concejos de Tíneo, Cangas del Narcea y Allande, muy cerca del castro de San Chuis), las características económicas del suelo (abundantes tajos mineros aprovechados por los romanos durante el Alto Imperio para obtener oro), la dedicatoria a Tutela (en conexión con la municipalización de las provincias occidentales del Imperio) y otros aspectos ${ }^{60}$ nos llevan a inclinarnos por dicho ámbito territorial de la cuenca del Arganza, afluente del Narcea, frente a la desembocadura del Nalón.

Por ello la importancia de Flavionavia como enclave de características especiales en el contexto del suelo habitado por los pésicos (y tal vez su principal centro de población tanto desde el punto de vista demográfico como político-administrativo y/o económico) ${ }^{61}$, si excluimos la identificación de la civitas de los pésicos con el recinto poblacional de San Chuis (hipótesis muy discutible), se aclara en la escueta referencia que de ella nos ha dejado Ptolomeo: no incluye dicho centro urbano entre los núcleos de población de los astures (tanto augustanos como transmontanos) ${ }^{62}$, aunque ubica el emplazamiento de dicha ciudad astur-romana con una precisión casi matemática de acuerdo con los grados, minutos y segundos de sus Tablas geográfico-históricas (dicho autor griego daría a la luz su Geografía en la segunda mitad del siglo ॥ (alrededor del 160 de nuestra era), momento en el que Flavionavia se había consolidado ya como el centro de población por excelencia de los pésicos, y de ahí que en su enumeración asigne a dicha población este centro urbano).

50 La onomástica indigena del dedicante, consignada en algunos otros documentos epigráficos del arco nordoccidental hispano. Ver, por ejemplo, CIL II.2523: Antistius Placidus (J.M. Blazouez, Religiones primitivas de Hispania, Madrid 1962, p.71) de Viana do Bollo; Pompeius Placidus (J.M. BlazQuez, Religiones, pág. 103) de Sigüenza; Ambatus Placidus (E. Marcos VaLLAURE, "Nuevas lápidas vadinienses de la provincia de León», Rierras de León n¹4 (1971) 77); CIL 11.2469: Quintus Fulvius Placidi filius (J.M. BLAzQUEZ, Religiones, p.132); CIL 11.2655 Placidus C.Licinii Himeri servus.

O bien CIL 11.4394: Placidius Lucius; 2640: Placidius Placidus; 5637: Placidius Seneca; 4394 : Placidius Severus; o 455: Placidia Modestis...

Sobre todo si tenemos en cuenta que ninguno de los dos castros próximos al ligar de hallazgo de la inscripción de la civitas de los pésicos, ni el Castillo de los moros en el término de Agüera (J.M. GONZALE2, Historia general de Asturias, 2: Asturias protohistórica, Salinas 1977, pág. 209) ni el de El Rebollar, localizado, al igual que el anterior y otros muchos de la región, por D. José Lombardía Zardain (los paisanos de la zona lo conocen simplemente con el nombre de El Castro), parecen haber adquirido a lo largo de su historia una entidad significativa.

Menciona exclusivamente a Lucus Asturum, Labernis, Interamnium, Argenteola, Lamciatum, Maliaca. Gigia, Bergidum Flavium, Interamnium Flavium y Legio VII Gemina. 
La fase de mayor florecimiento se vincularía con el momento de auge más intenso de la economía de la región ${ }^{63}$, las décadas de aprovechamiento a gran escala por parte de la administración romana de los recursos mineros del Suroccidente asturiano (sin olvidar el impulso que adquiriría sincrónicamente la producción agropecuaria como consecuencia de la puesta en explotación de las ricas vegas del Nalón y del Narcea).

El aprovechamiento de los recursos auríferos de las cuencas del Narcea y del Pigüeña (así como del territorio de algunos de sus afluentes más significativos, como el Arganza, el río del Oro y del Valledor, el río del Coto ${ }^{64} \ldots$ ) arrancaría de finales del siglo I, aunque la adaptación y puesta en funcionamiento de los mecanismos técnico-mineros ocuparía varias décadas.

Ahora bien, la implantación del sistema administrativo-territorial romano en el territorio de los pésicos no se produciría de golpe, sino que los indígenas necesitarían un período de tiempo para adaptarse a las nuevas condiciones de vida, así como para aceptar las innovaciones que tenian lugar en el seno de sus comunidades a todos los niveles (político, administrativo-territorial, social, ideológico-religioso...).

Este proceso, que en gran medida estaría acabado ya a mediados del siglo I (época de Nerón o inicios de los Flavios), daría muestras de inmadurez hasta las décadas finales de ese mismo siglo, momento que corresponde a la fase de máximo aprovechamiento de las minas por parte romana y en el que la población autóctona de los recintos castreños se iba a ver involucrada como mano de obra en los tajos de explotación ${ }^{65}$. Desde entonces la administración romana (por medio de los procuratores metallorum, libertos imperiales muchos de ellos, encargados del aprovechamiento de los centros de producción y de su evacuación en dirección a la capital del Imperio) hubo de articular un entramado de vias de comunicación e intercambios comerciales que facilitarían dicha tarea.

Se comprende asi la importancia cada vez mayor de Flavionavia por su ubicación en la desembocadura del Nalón y por convertirse en nudo de comunicaciones (sobre todo el camino costero, pero también el que transitaba por el interior relativamente próximo a la costa, así como el trazado

\footnotetext{
Que incidiria directamente en su conversión en municipio con todo lo que ello representaba para sus habitantes y los centros de habitat circundantes.

6. Ver, entre otros, N.SANTOS, "habitat y mineria romana del oro en el valle del rio del Coto (Cangas del Narcea-Asturias)". MHA 9 (1988) 21 ss.

Para más detalles ver N.SANTOS, «La mano de obra en las minas romanas del Occidente de Asturias", MHA 13-14 (1992-1993) 171ss., y "Los indigenas y la minería romana del oro en el Occidente de Asturias", MHA 18 (1997).
} 
final de la Vía de la Mesa en dirección al Cantábrico). En dicho enclave se concentrarian los excedentes (mineros, en especial el oro, y agropecuarios) para su traslado a otros centros del Occidente mediterráneo, incluida la propia Roma, donde la producción aurífera contribuía al mantenimiento de la economía imperial.

¿Cómo articuló la administración romana este circuito comercial?. Los caminos terrestres desempeñaban un papel destacado, al menos en la fase de recogida y concentración de la producción en un emplazamiento clave para su posterior distribución; junto a esta actividad en el ámbito de las vias terrestres no podemos desdeñar al mar como elemento de transmisión de esos productos económicos acumulados en el enclave de la ciudad romana de la desembocadura del Nalón ${ }^{65}$.

Las condiciones topográficas de la zona favorecerían este tipo de actividades por cuanto las mareas de época romana facilitarian la entrada de los barcos romanos por la misma debido a su profundidad, mucho mayor que en la actualidad ${ }^{67}$. Esa salida al mar se vería potenciada por la presencia continuada en el Cantábrico de una escuadra romana (classis Cantabrica), cuyos barcos llevaban surcando tan procelosas aguas al menos desde el momento de las campañas militares contra astures y cántabros en tiempos de Augusto; en consecuencia su actividad económica, vinculada a la evacuación de los productos mencionados, sería paralela a la desarrollada por la clasis Britannica en la región de Sussex (Gran Bretaña) durante el período que transcurre entre fines del siglo I y los inicios del III, en conexión en este último caso con la explotación de yacimientos de hierro ${ }^{68}$.

Esta función económica vitalizaría el ritmo de vida en Flavionavia desde los últimos años de la primera centuria de nuestra era, y de manera especial en las décadas de la segunda. En ese contexto no debemos olvidar el papel jugado por las villas astur-romanas que plagarian el suelo circundante, cuya producción agropecuaria pudo ser objeto de exportación (o de intercambios frecuentes y continuados) durante esa misma época.

Al igual que sucederia simultáneamente con otros centros de población astur-romanos, como Gijón (Gigia) por ejemplo, la ciudad romana de

\footnotetext{
Hasta la fecha no poseemos indicio de construcciones portuarias (o embarcaderu) en el contexto territorial dominado por dicho centro urbano.

El retroceso de la ría en pleamar se deja sentir en la vega de Santianes de Pravia o de Peñaulián (situada enfrente). mientras que en ei término de Riberas existen indicios en el cauce del rio de la presencia de amarraderos de barcos. cuya actividad se prolongaría cuando menos hasta el siglo xvill.

H. CIFEFE. "The Roman Iron Industry of the Weald and its Connections with the classis Britannica". AJ 131 (1974) 171 ss
} 
la desembocadura del Nalón dispondría, desde las décadas finales del siglo I, de una serie de establecimientos de esta naturaleza en su entorno, aún cuando únicamente en la centuria siguiente adquieran suficiente entidad ${ }^{69}$. Este tipo de poblamiento podemos rastrearlo en el solar de la aldea de Santianes, en concreto en el lugar denominado La Magdalena de la Llera ${ }^{70}$, o en las edificaciones que siglos después acogerían la residencia palaciega de Don Silo y Doña Adosinda, así como al edificio eclesial dedicado a san Juan.

Además, en un círculo de escasos kilómetros la toponimia de ciertos lugares, los restos de construcciones y murias, la presencia de fragmentos cerámicos de cierta antigüedad... nos ponen en conexión con la existencia de otro conjunto de centros de esta naturaleza en la cuenca del Nalón, en concreto en las localidades de Bances (valle de Posada), Los Cabos, Peñaullán, Riberas, Forcinas (con su extensa vega)..., así como, ya en la cuenca del Narcea poco antes de su entronque con el Nalón, en Quinzanas, Vegañán, Villanueva, Corias y Repolles, antes de llegar a Cornellana (concejo de Salas).

Estas villas astur-romanas, que en número superior a la docena flanquearian el emplazamiento de Flavionavia, aportarian, desde los años finales del siglo I, pero de manera especial en las décadas del siglo $\|$ y siguientes, el excedente de productos agrarios y ganaderos que generaban en su interior con vistas no sólo al abastecimiento y consumo de los habitantes del centro urbano sino también a las actividades comerciales de la zona ${ }^{71}$.

Apoyada en esta base económica agropecuaria, tal vez no experimentaría una decadencia tan acusada como otros poblados de los astures tras el declive en que se verian envueltos los centros de explotación minera, de los que sólo se nutriria como lugar de recepción, almacenamiento y evacuación de los mismos. Hasta el momento en que este decaimiento de la actividad en los tajos mineros (fines del siglo II) no se hizo ostensible la

En el caso del Gijón en época romana una veintena al menos de estos centros estarian asentados en el radio de acción de dicho enclave. Como exponente recordar, entre otros, el caso de las Murias de Beloño: cf. F. JonoA, Las Murias de Beloño (Cenero, Gijón): una villa romana en Asturias, Oviedo 1957.

Más detalles en J.M. GonzÁ.FZ, "Restos romanos de la Magdalena de la Llera (Santianes de Pravia)", págs. 201ss.

En un principio este centro astur-romano pudo funcionar como uno de los fora mencionados por Ptolomeo. es decir centro de convergencia de las actividades comerciales de dicho territorio, pasando a adquirir en los momentos iniciales del siglo II las características urbanistico-arquitectónicas que le perrnitirian alcanzar el estatuto de municipio. 
ciudad romana del Nalón por excelencia no experimentaría un constreñimiento económico, lo que trataría de remediar Caracalla al crear la provincia Hispania nova Citerior Antoniniana ${ }^{72}$.

A los problemas vinculados con la mano de obra según avanzamos en las postrimerías del siglo $\|$ en el marco de los aprovechamientos auríferos hay que añadir la escasa rentabilidad del terreno mineralizable objeto de explotación como algunas de las causas de este decaimiento en la obtención del oro ${ }^{73}$. Por otra parte, la conservación de la infraestructura hidráulica, junto con el mantenimiento tanto de la mano de obra utilizada en los pozos de explotación como del personal administrativo, técnico y militar, no justificarían unos gastos apenas compensados por los exiguos kilogramos de oro obtenidos.

Por ello en la segunda década del siglo III el emperador de los Severos mencionado daría origen a la nueva provincia hispanorromana del Noroeste, en la que se englobaban los tres conventus jurídicos de la región, cuyo territorio se identificaba con los distritos mineros de oro aprovechados por los romanos en las centurias precedentes. De esta manera, al margen de unos intereses politico-administrativos y/o militares que sin duda entrañaría (o precisamente en conexión con ellos), la creación de esta nueva circunscripción territorial adquiriría un sesgo económico evidente en cuanto suponía un intento de revitalización de las actividades económicas mineras ${ }^{74}$ con vistas a poner en explotación de nuevo dichos recursos auríferos.

Tales objetivos económicos parecen haber fracasado muy pronto, por lo que poco después colapsarian las explotaciones y desaparecería la nueva circunscripción administrativa provincial, cuya vigencia no rebasaría las dos décadas, tiempo suficiente para corroborar la no viabilidad de los objetivos perseguidos $^{75}$.

Como consecuencia de este debilitamiemto de las explotaciones mineras de oro Flavionavia experimentaría una decadencia en su funcionamiento, que en parte se vería paliada por la fuerza cada vez mayor adquirida por el conjunto de villas asentadas en el territorio de su en-

Detalles tratados en N. SANIOS, "La provincia Hispania nova Citerior Antoniniana". Boletin Brigantium $n^{\circ} 4$ (1983) $47 \mathrm{ss}$.

C. DOMERGut. «Les exploitations aurifères du Nord-ouest de la Péninsule lbérique sous l'occupation romaine". La mineria hispana e iberoamericana, León 1970. págs. 174-175

Posiblemente el último a gran escala por parte de la administración romana.

Dicho territorio pasaria a integrarse de nuevo bajo el mando único del legado propretor de la provincia Hispania Citerior Tarraconense. 
torno ${ }^{76}$. Se daría paso así a una ruralización de dicho centro urbano, perdiendo, según nos adentramos en el siglo ॥l, su importancia como centro político-administrativo, económico y viario que había mantenido durante muchas décadas del Alto Imperio, en especial las últimas.

En este contexto hemos de preguntarnos por la importancia del espacio urbano correspondiente a Flavionavia en el momento de mayor esplendor, así como su posible amurallamiento a medida que nos adentramos en los momentos de costreñimiento económico (y posiblemente territorial). Al contrario de lo que sucede en el caso de Gigia por ejemplo ${ }^{77}$, resulta imposible delimitar su espacio habitado, ni siquiera de manera aproximada, puesto que hasta la fecha ni su emplazamiento se ha logrado ubicar con precisión; tampoco existen indicios sobre un hipotético proceso de amurallamiento en dicho enclave, que, en el caso de haberse producido, tendría como ámbito temporal la etapa bajoimperial, pudiendo dar lugar a una reducción en el espacio habitado, como al parecer sucedería con respecto al Gijón romano.

La topografía del emplazamiento de este centro urbano en Santianes de Pravia nos lleva a pensar que el muro que lo rodeaba incluiría en su interior todo, o casi todo, el conjunto de construcciones correspondientes a dicho asentamiento poblacional; de esta forma es posible establecer un cierto paralelismo ${ }^{78}$ con los recintos amurallados de Lucus Augusti (Lugo) y Bracara Augusta (Braga) ${ }^{79}$. Como no disponemos de las medidas de la zona habitada, difícilmente se podrá calibrar la amplitud de la demografía de dicho enclave: su casco urbano no se asemejaría al de otro centros romanos del Noroeste peninsular ${ }^{80}$, pero su importancia económica y de nudo de comunicaciones nos indica que no sería menor que el propio del Gijón romano (en torno a las 5 Has. habitadas) ${ }^{81}$.

Nos encontramos, pues, ante una ciudad de dimensiones reducidas en comparación con los núcleos de población hispanorromanos más sobresalientes de la Península; este mismo paralelismo resulta favorable si com-

\footnotetext{
Perderia su actividad como centro de relaciones maritimas y comerciales, sobre el que se apoyaba desde finales del siglo I, hasta el punto de que se la asigne el primer lugar entre las poblaciones marítimas del conventus de los astures.

N. Santos, "Gigia, la ciudad romana de Gijón", págs. 227-228.

Solamente en este aspecto, no en extensión ni en importancia administrativo-territorial.

En lo que respecta al último de estos casos remitimos, entre otros, a P. LE Roux, «Aux origines de Braga (Bracara Augusta)», Bracara Augusta 29 (1975) 155ss

so Lucus Augusti por ejemplo cuenta con un recinto amurallado de unas 28 Has. mientras que el perimetro de Asturica Augusta ronda las 26 Has.

N. SANTOS, "Gigia, la ciudad romana de Gijón», pág. 227
} 
paramos dichas dimensiones con las de los poblados castreños romanizados del Noroeste ubicados a uno y otro lado de la cordillera cantábrica, que en el mejor de los casos a duras penas rebasarían las 2 Has. ${ }^{82}$.

La historiografía actual esta de acuerdo en asignar como densidad de población en tiempos romanos por hectárea unos 300 habitantes (o un número algo mayor cuando las circunstancias topográficas de algunos enclaves eran favorables); esto nos lleva a calcular para el caso de Flavionavia una población próxima a los 1.000 habitantes al menos durante las décadas del Alto Imperio de mayor florecimiento.

No puede extrañarnos que, en la época de mayor desarrollo, este enclave de población astur-romana dispusiese de un censo de población que tardaría muchos siglos en verse superado por la actual capital del concejo, puesto que la fundación de Pravia remonta a los siglos finales de la época medieval tras un proceso fácil de entender: tras la desintegración de la organización imperial romana, tanto el comercio como las relaciones marítimas que tenían a Flavionavia como centro cesarían, de manera que, con el paso de los siglos, surgiría (teniendo al conjunto de villas de la zona como baluarte) un núcleo de influencia comarcal cada vez más fuerte, lo que se traduciría en la necesidad de constituir una puebla fortificada, en torno a la cual gravitarían todos los asentamientos rurales de su entorno ${ }^{83}$.

Resulta lógico suponer que, en el transcurso de los siglos III y IV, este centro urbano de la desembocadura del Nalón, como consecuencia de los avatares negativos que envolvieron al Norte peninsular ( $y$ en general a todas las provincias del Imperio) ${ }^{84}$, experimentaría un retroceso en su actividad económica y ritmo de vida cotidiano. Ello no supondria que los siglos de oscuridad que se abrían en la historia de Flavionavia iban a arrastrar cambios bruscos en las formas de vida de sus habitantes, lo que sin duda acarrearía un descenso demográfico acusado, en parte porque los pobladores de dicho centro se desplazarían a las villas, que continuarían vinculadas al mismo para su funcionamiento.

Asi pues, si en época altoimperial la economía había basculado en torno a las actividades comerciales ( $y$ en menor grado mineras), al tiempo que el sector industrial arraigaría con fuerza y el agropecuario tampoco

\footnotetext{
Por ejemplo los recintos de San Chuis (Allande) o de Coaña, prototipos del poblamiento castreño astur-romano durante los siglos del Alto Imperio.

De esta manera se convertiria en el territorium Praviae documentado en la diplomática medieval

¿ Para ahondar en estas cliestiones de carácter económico-social además de político-administrativas remitimos, entre otros, a M. VIGH y A. BARBERO, "Algunos problemas sociales del Norte de la Península a fines del Imperio Romano", PLAV 5 (1968) 81ss.. y N. SANTOS, "Movimientos sociales en la España del Bajo Imperio". Hispania 40 (1980) 237ss
} 
sería desdeñable, la etapa del Bajo Imperio coincidiría con un predominio del sector agropecuario sobre el industrial y comercial ${ }^{85}$.

¿Qué sucedería con Flavionavia en los siglos finales de la Antigüedad, incluida la fase visigoda? Dicho emplazamiento difícilmente puede identificarse con el Passicin que nos documenta el Anónimo de Rávena ${ }^{86}$, y tampoco con los topónimos "Pésicos" (parroquia sueva) y "Pésicos" (ceca de emisión en tiempos visigodos) ${ }^{87}$. Tales referencias históricas parecen relacionarse con la civitas Paesicorum ya en los siglos bajoimperiales y visigodos, momento en el que, por una parte, el cristianismo arraigaría en la zona y aceptaría los parámetros propios de la organización administrativa romana, y, por otra, este antiguo centro de control y articulación territorial de uno de los más importantes distritos mineros de oro del Occidente de Asturias volvería a recuperar las antiguas funciones políticas que en parte explicarian su razón de ser.

Frente a la identificación Passicin = Flavionavia, defendida hace años ${ }^{88}$ se impone cada vez más entre los estudiosos la propuesta de Diego Santos en el sentido de que dicho centro urbano alteraría su nombre con el paso de los años hasta identificarse con el núcleo de población que el Anónimo de Rávena denomina Amneni, calificativo (de la raíz latina amnis) que se traduce como "ciudad del rio", puesto que la corriente fluvial por excelencia de Asturias desde los tiempos más remotos se identifica con el río Nalón y su desembocadura.

En la última fase del mundo antiguo (tiempos visigodos) la mayor fuerza económico-social de la región no vendría representada ya por el antiguo centro urbano astur-romano más importante del territorio de los pésicos sino por el auge cada vez mayor experimentado por las villas de sus alrededores. Así pues, a pesar de que sin duda se vería afectada por los avatares de las invasiones suevas en las regiones septentrionales hispanas (sobre todo por constituir el final de una de las más importantes vías de comunicación romana) ${ }^{89}$, los habitantes de esta región próxima a la desembocadura del Nalón atravesarian por un periodo de calma y paz en conexión con las actividades agropecuarias propias de estos centros rurales de habitat durante las décadas finales de la Antigüedad.

\footnotetext{
85 Ambos continuarian teniendo fuerza, aunque reducidos a un círculo de producción doméstica.

86 J. SANTOS, "Asturias en la organización político-administrativa romana de Hispania en época altoimperial», pág. 155.

8: Para más detalles sobre este último punto ver, entre otros, N. SANTOS y C. VERA, «Emisiones monetales visigodas en Asturias", / Encontro Peninsular de Numismatica Antiga, Oporto 1998 (en prensa).

B8 J.M. GonzÁlEZ, El litoral asturiano en la época romana, Oviedo 1954, págs. 198ss.

ag Por lo que no puede extrañar la emisión monetaria llevada a cabo por Gundemaro y Sisebuto en el territorio de la antigua civitas Paesicorum.
} 